\title{
THE EFFICIENCY AND OPTIMAL SIZE OF TRIPLE TEST CROSS DESIGNS FOR DETECTING EPISTATIC VARIATION
}

\author{
H. S. POONI and J. L. JINKS \\ Department of Genetics, University of Birmingham, Birmingham B15 2TT
}

Received 1.iii.75

\begin{abstract}
SUMmaRY
The triple test cross and two of its associate designs have been compared for their theoretical and practical efficiency in detecting epistatic variation. The comparisons are made on the basis of optimal experimental sizes required for each of these tests to detect a modest level of epistasis significantly $(P \leqq 0.05)$ and with a reasonable certainty (95 per cent). The experimental sizes are determined for various combinations of heritability, dominance ratio and gene association and for both duplicate and complementary epistasis.

Two versions of the test of epistasis designed by Kearsey and Jinks (1968), Test $1 \mathrm{a}$ and Test $1 \mathrm{~b}$, do not differ much in their theoretical efficiency for detecting epistasis and the optimal experimental sizes required by them to detect non-allelic interactions significantly are largely impracticable except when dominance and heritability are high and the degree of association is 50 per cent or more. Both the tests require much smaller experiments to detect duplicate epistasis than complementary epistasis of the same magnitude and this difference is more pronounced for lower levels of heritability and dominance. The theoretical efficiency of Test 2 (given by Jinks, Perkins and Breese, 1969), however, does not vary with the type of epistasis but the sensitivity of the test is inversely related to the degree of gene association between the tester parents.

The practical implications of the present investigation are discussed and the validity of some of the most important theoretical predictions and assumptions are tested on a triple test cross involving 80 inbred lines of Nicotiana rustica.
\end{abstract}

\section{INTRODUGTION}

THE triple test cross (Kearsey and Jinks, 1968) and its various modifications and extensions (Jinks, Perkins and Breese, 1969; Jinks and Perkins, 1970; Perkins and Jinks, 1970) are among the best designs available for the study of the genetical architecture of randomly breeding populations. These designs provide separate tests for, and estimates of the additive, dominance and epistatic components of variability but the presence of additive or dominance components can only be tested for unambiguously and unbiased estimates obtained in the absence of epistasis. Efficient detection of epistasis, therefore, is an important objective of the triple test cross design.

Non-allelic interactions, when large in magnitude, are easily detected by any of the tests available from modestly designed experiments. In general, however, epistasis is not expected to be present on a large scale and will normally be a minor portion of the total variation. (Mather and Jinks, 1971). In these circumstances the detection of epistasis will be dependent upon the size of the experiment conducted and the efficiency of the test applied.

The problems of optimal size and efficiency have been considered by 
Kearsey (1970) and Pederson (1971) in respect of the additive and dominance variation in a number of multiple mating designs. They observed that the maximum information could be extracted by allowing family size $(m)$ to vary with the genetical situation and calculating the optimum number of families $(n)$ for the particular experimental design. One objective of this study is to calculate the value of $n$ required to optimise the efficiency of an experiment.

The efficiency of any test to detect epistasis or any other type of gene action will depend on the ratio $\sigma_{2}^{2} / \sigma_{1}^{2}$ where the magnitudes of these components are direct functions of various genetic and environmental components of variation. The procedure will be to calculate the theoretical expectations of $\sigma_{1}^{2}$ and $\sigma_{2}^{2}$ for various tests and their relative magnitudes obtained theoretically for the limiting case of $d_{j}=d, h_{j}=h, i_{j k}=i, l_{j k}=1$ and $j_{k j}=j_{j k}=j$ for all the loci involved where $d$ and $h$ are the additive and dominance effects of the genes and $i, j$ and $l$ are the epistatic effects (Mather and Jinks, 1971). To calculate the size of the experiment required to detect a given amount of epistasis with a particular level of statistical reliability it will be necessary to define the inter-relationships between the magnitudes of these various genetical and non-genetical components of variation for a variety of situations. These theoretical predictions will be related to the results of triple test crosses between inbred lines of Nicotiana rustica.

\section{TESTS OF EPISTASIS}

The first test (Test la) is that given by Kearsey and Jinks (1968) and can be presented as a variance ratio $(A)$

where

$$
A=\frac{m \times V\left(\bar{L}_{1 i}+\bar{L}_{2 i}-2 \bar{L}_{3 i}\right)+\left(\bar{V} L_{1}+\bar{V} L_{2}+4 \bar{V} L_{3}\right)}{\left(\bar{V} L_{1}+\bar{V} L_{2}+4 \bar{V} L_{3}\right)} .
$$

Here, $m$ is the family size; $L_{1 i}, L_{2 i}$ and $L_{3 i}$ are the means of families produced by crossing the $i$ th individual of an $F_{2}$ to $P_{1}, P_{2}$ and $F_{1}$ testers respectively and $\bar{V} L_{1}, \bar{V} L_{2}$ and $\bar{V} L_{3}$ are the average within variances of these $L_{1 i}, L_{2 i}$ and $L_{3 i}$ families respectively. For an experiment involving $n \mathrm{~F}_{2}$ parents, the degrees of freedom of this V.R.(A) are $n$, and $3 n(m-1)$.

The second test (Test $\mathrm{lb}$ ) is a modification of Test la in which $\mathrm{F}_{2}$ individuals are replaced by a random sample of $F_{\infty}$ inbreds in the crossing programme. Test $\mathrm{la}$ and Test $\mathrm{lb}$ will therefore use the same analytical procedures but are expected to have different genetical expectations.

The third test (Test 2), as described by Jinks, Perkins and Breese (1969), is only applicable to $\mathrm{F}_{\infty}$ inbreds and is based on their $L_{1 i}$ and $L_{2 i}$ families. No $L_{3 i}$ families are required and the test takes the form:

$$
A=\frac{m \times V\left(\bar{L}_{1 i}+\bar{L}_{2 i}-\bar{P}_{i}\right)+\left(\bar{V} L_{1}+\bar{V} L_{2}+\bar{V} P\right)}{\left(\bar{V} L_{1}+\bar{V} L_{2}+\bar{V} P\right)} .
$$

Here, $\bar{P}_{i}$ is the mean of $i$ th inbred and $\overline{V P}$ the average variation within inbred families. The degrees of freedom in this case are $(n-1)$ and $3 n(m-1)$.

The theoretical expectations of various statistics involved in these tests are given in table 1 . Where $E$ stands for the environmental component of variation and the additive, dominance and epistatic gene effects are defined according to the $\mathrm{F}_{\infty}$ metric discussed by Van der Veen (1959). The number of loci segregating for a character are denoted by $K$ and the symbol ' $r$ ' 
represents the coefficient of gene association in the parental genotypes (Jinks and Jones, 1958).

\section{Estimation of EXPERIMENTAL Sizes}

The tests of epistasis can take the form $A=1+m \sigma_{2}^{2} / \sigma_{1}^{2}$ where $\sigma_{1}^{2}$ and $\sigma_{2}^{2}$ are $\left(\bar{V} L_{1}+\bar{V} L_{2}+4 \bar{V} L_{3}\right)$ and $V\left(L_{1 i}+L_{2 i}-2 L_{3 i}\right)$ respectively for Test la and Test $1 \mathrm{~b}$ and $\left(\bar{V} L_{1}+\bar{V} L_{2}+\bar{V} P\right)$ and $V\left(L_{1 i}+L_{2 i}-\bar{P}_{i}\right)$ for Test 2. The degrees of freedom for each of these tests will depend upon the number of families to be included in the experiment and the number of sibs to be raised for each of these families. For most plant breeding and biometrical genetical experiments the total number of individuals raised runs into several hundred.

\section{TABLE 1}

Genetical and environmental expectations of various statistics which have been used in various tests of epistasis*

$$
\begin{aligned}
& \text { Statistic } \\
& \mathrm{F}_{\mathbf{2}} \text { population Expectation } \\
& V\left(L_{1 i}+L_{2 i}-2 L_{3 i}\right) \quad \frac{1}{4}[i]^{2}+\frac{1}{8} \Sigma j_{j k}^{2}+\frac{1}{16} \Sigma l_{j k}^{2}+\frac{1}{8}\left[\Sigma j j k \sum j_{s k}\right] \\
& \bar{V} L_{1}+\bar{V} L_{2} \quad \quad \frac{1}{4} \Sigma d_{j}^{2}+\frac{1}{4} \Sigma h_{j}^{2}+\frac{7}{32}\left\{\Sigma i_{j k}^{2}+\Sigma j_{j k}^{2}+\Sigma l_{j k}^{2}\right\} \pm \frac{1}{4} \Sigma d_{j j} j_{j k} \\
& \pm \frac{1}{4}\left[\sum d_{j} j_{k j}\right] \pm \frac{1}{4} \sum l_{j k}\left(h_{j}+h_{k}\right) \mp \frac{1}{4}\left[\sum i_{j k}\left(h_{j}+h_{k}\right)\right] \\
& +\frac{1}{8} \Sigma l_{j k}\left(\Sigma l_{j s}+\Sigma l_{s j}+\Sigma l_{s k}+\Sigma l_{k s}\right)-\frac{1}{16}\left[\Sigma i_{j k} l_{j k}\right] \\
& -\frac{1}{8}\left[\Sigma i_{j k}\left(\Sigma l_{j s}+\Sigma l_{s j}+\Sigma l_{s k}+\Sigma l_{k s}\right)\right]+\frac{1}{8}\left[\Sigma j_{j k}\left(\Sigma j_{j s}+\Sigma j_{s k}\right)\right] \\
& +\frac{1}{8}\left[\sum i_{j k}\left(\sum i_{j s}+\sum i_{s j}+\sum i_{s k}+\sum i_{k s}\right)\right]-\frac{1}{16}\left[\Sigma j_{j k} j_{k j}\right] \\
& -\frac{1}{8}\left[\sum j_{j k}\left(\sum j_{s j}+\sum j_{k s}\right)\right]+2 E \\
& \bar{V} L_{3} \quad \quad \frac{3}{8} \Sigma d_{j}^{2}+\frac{1}{4} \Sigma h_{j}^{2}+\frac{15}{84} \Sigma i_{j k}^{2}+\frac{7}{32} \Sigma j_{j k}^{2}+\frac{3}{16} \Sigma l_{j k}^{2} \\
& \pm \frac{3}{8} \Sigma d_{j} j_{j k} \pm \frac{1}{4} \Sigma l_{j k}\left(h_{j}+h_{k}\right)+\frac{3}{32} \Sigma j_{j k} \Sigma j_{j s} \\
& +\frac{1}{16} \Sigma l_{j k}\left(\Sigma l_{j s}+\Sigma l_{s j}+\Sigma l_{k s}+\Sigma l_{s k}\right)+E \\
& V\left(L_{1 i}+L_{2 i}-2 L_{3 i}\right) \quad \frac{1}{4}\left\{[i]^{2}+\Sigma j_{j k}^{2}+\Sigma l_{j k}^{2}\right\}+\frac{1}{4}\left[\Sigma j_{j k} \Sigma j_{s k}\right] \\
& V\left(L_{1 i}+L_{2 i}-\bar{P}_{i}\right) \quad \frac{1}{4} \sum i_{j k}^{2}+\frac{1}{2} \Sigma j_{j k}^{2}+\frac{1}{4} \Sigma l_{j k}^{2}-\frac{1}{2}\left[\Sigma i_{j k} l_{j k}+\Sigma j j_{j k j k j}\right] \\
& +\frac{1}{4}\left[\Sigma j_{j k}\left(\Sigma j_{j s}+\Sigma j_{s j}+\Sigma j_{k s}+\Sigma j_{s k}\right)\right] \\
& \bar{V} P, \bar{V} L_{1}, \bar{V} L_{2} \\
& \text { E } \\
& \widetilde{V} L_{3} \\
& \frac{1}{4} \Sigma d_{j}^{2}+\frac{1}{4} \Sigma h_{j}^{2}+\frac{3}{16}\left\{\Sigma i_{j k}^{2}+\sum j_{j k}^{2}+\Sigma l_{j k}^{2}\right\} \pm \frac{1}{4} \Sigma l_{j k}\left(h_{j}+h_{k}\right) \\
& \pm \frac{1}{4} \Sigma d_{j j} j_{j k}+\frac{1}{16} \Sigma j_{j k} j_{j s}+\frac{1}{16} \Sigma l_{j k}\left(\Sigma l_{l_{s}}+\Sigma l_{s j}+\Sigma l_{k s}+\Sigma l_{s k}\right)+E
\end{aligned}
$$

* Lower signs are for duplicate genes, and each value in a square bracket is a function of the coefficient of gene association. Subscript $s$ equals 1 to $K$ but not $j$ or $k$.

The value of $3 n(m-1)$ is usually very large and much larger than $n$ or $n-1$. Thus following Kearsey (1970), variance ratios can be replaced by $\chi^{2}$ such that

$$
\chi_{\left(\alpha_{1}\right)}^{2} / \chi_{\left(\alpha_{2}\right)}^{2}=1+m \sigma_{2}^{2} / \sigma_{1}^{2} \ldots(1) .
$$

Where $\alpha_{1}$ and $\alpha_{2}$ have the probability values of 0.05 and 0.95 respectively, the $\chi_{(0.05)}^{2}$ and $\chi_{(0.95)}^{2}$ values for any number of degrees of freedom can be obtained from the statistical tables. 
Following equation (1) and for a given number of families the optimal family size for, say, Test la will be

$$
m=\left\{\left(\chi_{(0.05)}^{2} / \chi_{(0.95)}^{2} \text { for } n \text { d.f. }\right)-1\right\} \times\left(\sigma_{1}^{2} / \sigma_{2}^{2}\right) .
$$

The total experimental size $(3 \mathrm{~nm})$ will, then, be given by

$$
3 n\left\{\left(\chi_{(0.05)}^{2} / \chi_{(0.95)}^{2} \text { for } n \text { d.f. }\right)-1\right\}\left(\sigma_{1}^{2} / \sigma_{2}^{2}\right)
$$

Thus the size of the experiment is theoretically linked to the magnitudes of three quantities, namely, $3 n,\left(\chi_{(0.05)}^{2} / \chi_{(0.95)}^{2}-1\right)$ and $\sigma_{1}^{2} / \sigma_{2}^{2}$. Quantity $3 n$ is linearly related to $n$ whereas $\left(\chi_{(0.05)}^{2}\left(\chi_{(0.95)}^{2}-1\right)\right.$ has a negative but curvilinear relationship with the number of families. The product

$$
3 n\left(\chi_{(0.05)}^{2} / \chi_{(0.95)}^{2}-1\right)
$$

in fact has a minimum and at an intermediate value of $n$.

The magnitudes of

and

$$
T_{1}\left(=3 n\left(\chi_{(0.05)}^{2} / \chi_{(0.95)}^{2}(\text { for } n \text { d.f. })-1\right)\right)
$$

$$
T_{2}\left(=3 n\left(\chi_{(0.05)}^{2} / \chi_{(0.95)}^{2}(\text { for } n-1 \text { d.f. })-1\right)\right.
$$

have, therefore, been worked out for various tests and for $n$ equals 3 to 80 . The results obtained are listed in table 2. For Test la and Test $1 \mathrm{~b} n=12$ while for Test $2 n=15$ for the smallest values of $T_{1}$ and $T_{2}$ respectively.

The third unknown quantity required to calculate the experimental sizes is $\sigma_{1}^{2} / \sigma_{2}^{2}$. Our interest lies in this ratio rather than in the absolute magnitudes of $\sigma_{1}^{2}$ and $\sigma_{2}^{2}$. The relative magnitudes of genetic and non-genetic components involved in the expectations of $\sigma_{1}^{2}$ and $\sigma_{2}^{2}$ can be presented therefore as proportions which can be derived from the interrelationships of these components. The commonest relationships in biometrical genetics are heritability $\left(h_{n}^{2}\right)$ and dominance ratio. The proportionate values of the additive, dominance and environmental components can thus be obtained for varying genetic situations by changing $h_{n}^{2}$ and the dominance ratio while keeping the total phenotypic variance as unity in the absence of epistasis.

There are no corresponding relationships involving epistasis. One reason is the large number of possible relationships and another is the non-availability of proper estimates of various epistatic components of variance. However, some useful relationships between epistatic and non-epistatic effects are theoretically possible because of the way the various epistatic components are defined, but for our present purposes we are less interested in defining these relationships than obtaining a realistic range of relative values for the epistatic components. We therefore, chose the relationships:

and

$$
\Sigma i_{j k}^{2}=\frac{1}{10} \Sigma d_{j}^{2}, \quad \Sigma j_{j k}^{2}=\frac{1}{10}\left(\Sigma d_{j}^{2}+\Sigma h_{j}^{2}\right)
$$

$$
\Sigma l_{j k}^{2}=\frac{1}{10} \Sigma h_{j}^{2}
$$

These epistatic components together with $\Sigma d_{j}^{2}, \Sigma h_{j}^{2}$ and $E$ were calculated for the following combinations of heritability and dominance ratio.

$$
\begin{aligned}
h_{(n)}^{2} & =0.25,0.50,0.75 \\
\text { dominance ratio } & =0.25,0.50,0.75,1.00
\end{aligned}
$$


$\kappa$, the number of genes segregating for a character was taken to be 10 and ' $r$ ' the coefficient of gene association, was allotted the values of $0 \cdot 0,0 \cdot 2,0 \cdot 4$, $0 \cdot 6,0.8$ and $1 \cdot 0$.

\section{TABLE 2}

The expected values of $\mathrm{T}_{1} *$ and $\mathrm{T}_{2} \dagger$ for different number (n) of families to be raised in an experiment

$\begin{array}{rcc}n & { }^{*} T_{1} & \dagger T_{2} \\ 3 & 190 \cdot 82 & 514 \cdot 49 \\ 4 & 148 \cdot 13 & 254 \cdot 42 \\ 5 & 130 \cdot 02 & 185 \cdot 17 \\ 6 & 120 \cdot 63 & 156 \cdot 03 \\ 7 & 115 \cdot 32 & 140 \cdot 73 \\ 8 & 112 \cdot 17 & 131 \cdot 79 \\ 9 & 110 \cdot 39 & 126 \cdot 20 \\ 10 & 109 \cdot 39 & 122 \cdot 65\end{array}$

$\begin{array}{ccc}n & T_{1} & T_{2} \\ 11 & 108 \cdot 92 & 120 \cdot 33 \\ 12 & 108 \cdot 84 & 118 \cdot 83 \\ 13 & 109 \cdot 02 & 117 \cdot 91 \\ 14 & 109 \cdot 38 & 117 \cdot 40 \\ 15 & 109 \cdot 91 & 117 \cdot 20 \\ 16 & 110 \cdot 52 & 117 \cdot 24 \\ 17 & 111 \cdot 24 & 117 \cdot 43 \\ 18 & 112 \cdot 02 & 117 \cdot 78\end{array}$

$\begin{array}{ccc}n & T_{1} & T_{2} \\ 19 & 112 \cdot 83 & 118 \cdot 24 \\ 20 & 113 \cdot 68 & 118 \cdot 77 \\ 30 & 123 \cdot 03 & 127 \cdot 13 \\ 40 & 132 \cdot 40 & 135 \cdot 71 \\ 50 & 141 \cdot 27 & 144 \cdot 10 \\ 60 & 149 \cdot 60 & 152 \cdot 09 \\ 70 & 157 \cdot 44 & 159 \cdot 69 \\ 80 & 164 \cdot 90 & 166 \cdot 94\end{array}$

$$
\begin{aligned}
& * T_{1}=3 n\left(\frac{\chi^{2}(0 \cdot 05)}{\chi^{2}(0 \cdot 95)}(\text { for } n \text { d.f. })-1\right) \\
& +T_{2}=3 n\left(\frac{\chi^{2}(0 \cdot 05)}{\chi^{2}(0 \cdot 95)}(\text { for } n-1 \text { d.f. })-1\right)
\end{aligned}
$$

TABLE 3

Minimum experimental sizes for detecting epistasis from a TTC involving $F_{2}$ individuals

\begin{tabular}{|c|c|c|c|c|c|c|c|}
\hline \multirow[b]{2}{*}{$h_{n}^{2}$} & \multirow{2}{*}{$\begin{array}{l}\text { Dominance } \\
\text { ratio }\end{array}$} & \multicolumn{6}{|c|}{ Degree of gene association in the tester parents } \\
\hline & & 0.00 & $0 \cdot 20$ & $0 \cdot 40$ & 0.60 & $0 \cdot 80$ & $1 \cdot 00$ \\
\hline \multirow{8}{*}{$0 \cdot 25$} & \multirow[t]{2}{*}{$0 \cdot 25$} & 91380 & 124100 & 55655 & 10311 & 2932 & $1125 \ddagger$ \\
\hline & & 65792 & 89581 & 40487 & 7598 & 2200 & 864 \\
\hline & \multirow[t]{2}{*}{$0 \cdot 50$} & 87745 & 108686 & 49103 & 10102 & 2957 & 1144 \\
\hline & & 58328 & 72488 & 33077 & 6919 & 2073 & 826 \\
\hline & \multirow[t]{2}{*}{0.75} & 82688 & 91625 & 41746 & 9808 & 3003 & 1179 \\
\hline & & 48454 & 53911 & 24865 & 5962 & 1879 & 765 \\
\hline & \multirow{2}{*}{$1 \cdot 00$} & 77185 & 77004 & 35339 & 9466 & 3061 & 1228 \\
\hline & & 38258 & 38355 & 17861 & 4902 & 1640 & 687 \\
\hline \multirow{8}{*}{0.50} & \multirow[t]{2}{*}{$0 \cdot 25$} & 49931 & 67748 & 30299 & 5587 & 1578 & 600 \\
\hline & & 24342 & 33229 & 15132 & 2875 & 846 & 339 \\
\hline & \multirow[t]{2}{*}{0.50} & 49750 & 61549 & 27707 & 5665 & 1644 & 628 \\
\hline & & 20332 & 25351 & 11680 & 2482 & 759 & 311 \\
\hline & \multirow[t]{2}{*}{0.75} & 49326 & 54583 & 24767 & 5778 & 1752 & 679 \\
\hline & & 15093 & 16870 & 7887 & 1933 & 627 & 265 \\
\hline & \multirow[t]{2}{*}{$1 \cdot 00$} & 48689 & 48508 & 22168 & 5896 & 1887 & 746 \\
\hline & & 9762 & 9859 & 4691 & 1332 & 466 & 206 \\
\hline \multirow{4}{*}{0.75} & \multirow[t]{2}{*}{$0 \cdot 25$} & 36115 & 48963 & 21847 & 4013 & 1127 & 425 \\
\hline & & 10526 & 14444 & 6670 & 1300 & 395 & - \\
\hline & \multirow[t]{2}{*}{0.50} & 37085 & 45837 & 20574 & 4186 & 1206 & 456 \\
\hline & & 7667 & 9639 & 4548 & 1003 & 322 & - \\
\hline
\end{tabular}

Degree of gene association in the tester parents

- The expected minimal experimental size is of less than 200 individuals.

* Upper and lower figures represent the experimental sizes required to detect complementary and duplicate epistasis respectively.

$36 / 2-\mathrm{E}$ 
The minimal experimental sizes were only computed for the relationship between $i, j$ and $l$ consistent with duplicate and complementary epistasis since non-allelic interactions in general can only be classified into these two types for quantitative traits (Jinks and Jones, 1958). The figures obtained have been tabulated in tables 3,4 and 5. Before we draw any conclusions from these theoretical results we shall test the applicability of some of the assumptions in a practical solution.

TABLE 4

Minimum experimental sizes for detecting epistasis from a TTC involving $F \infty$ inbreds

\begin{tabular}{|c|c|c|c|c|c|c|c|}
\hline \multirow[b]{2}{*}{$h_{n}^{2}$} & \multirow{2}{*}{$\begin{array}{l}\text { Dominance } \\
\text { ratio }\end{array}$} & \multicolumn{6}{|c|}{ Degree of gene association in the tester parents } \\
\hline & & $0 \cdot 00$ & $0 \cdot 20$ & $0 \cdot 40$ & $0 \cdot 60$ & $0 \cdot 80$ & $1 \cdot 00$ \\
\hline \multirow{8}{*}{$0 \cdot 25$} & $\quad 0.25$ & 56402 & 54750 & 21948 & 5660 & 1851 & $760+$ \\
\hline & & 53263 & 51702 & 20726 & 5344 & 1748 & $718^{\circ}$ \\
\hline & $0 \cdot 50$ & 43428 & 39692 & 17730 & 5036 & 1731 & 726 \\
\hline & & 40210 & 36751 & 16046 & 4663 & 1602 & 672 \\
\hline & 0.75 & 31093 & 26924 & 12716 & 4231 & 1555 & 674 \\
\hline & & 27823 & 24092 & 11379 & 3786 & 1392 & 603 \\
\hline & $1 \cdot 00$ & 21908 & 18256 & 9128 & 3423 & 1352 & 609 \\
\hline & & 18622 & 15518 & 7759 & 2910 & 1150 & 517 \\
\hline \multirow{8}{*}{0.50} & 0.25 & 20916 & 20303 & 8139 & 2099 & 687 & 282 \\
\hline & & 17777 & 17256 & 6917 & 1784 & 584 & 240 \\
\hline & 0.50 & 15769 & 14413 & 6293 & 1829 & 628 & 264 \\
\hline & & 12552 & 11472 & 5009 & 1456 & 500 & 210 \\
\hline & $0 \cdot 75$ & 10870 & 9413 & 4446 & 1479 & 544 & 236 \\
\hline & & 7590 & 6581 & 3108 & 1034 & 380 & - \\
\hline & $1 \cdot 00$ & 7214 & 6012 & 3006 & 1127 & 445 & 200 \\
\hline & & 3929 & 3274 & 1637 & 614 & 243 & - \\
\hline \multirow{4}{*}{0.75} & $0 \cdot 25$ & 9088 & 8821 & 3536 & 912 & 298 & - \\
\hline & & 5948 & 5774 & 2315 & 597 & - & - \\
\hline & 0.50 & 6550 & 5987 & 2614 & 760 & 261 & - \\
\hline & & 3332 & 3046 & 1330 & 386 & - & 一 \\
\hline
\end{tabular}

\section{The eXPeriment}

The experiment involved 80 inbreds each produced by consecutive selfing to $F_{11}$ of a single randomly chosen $F_{2}$ individual from a cross between varieties 1 and 5 of Nicotiana rustica (Mather and Vines, 1952). Individual plants from each of these inbred families were selfed and crossed to $\mathrm{P}_{1}, \mathrm{P}_{5}$ and their $\mathrm{F}_{1}$ to produce $P_{i}, L_{1}, L_{2 i}$ and $L_{3 i}$ families. Ten replicates were raised for each of these $80 \times 4$ families and the material was grown as a part of a larger experiment conducted during the summer of 1973. Single plant randomisation was practised and all the plants were scored individually for the following morphological characters.

1. Height $(\mathrm{cm})$ of individual plants; 2 weeks $\left(\mathrm{H}_{1}\right), 4$ weeks $\left(\mathrm{H}_{2}\right)$ and 6 weeks $\left(\mathrm{H}_{3}\right)$ after planting in the field.

2. Number of days taken to flower from lst June (FT). 
3. Height $(\mathrm{cm})$ at flowering time (HFT).

4. Corolla length $(\mathrm{cm})$ at the time of flowering (CL).

5. Stamen stigma heights (relative) of the first (open) flower (SSP).

6. Leaf length $(\mathrm{cm})$ of the largest leaf (blade) at the time of flowering (LL).

7. Leaf width $(\mathrm{cm})$ of the largest leaf (blade) at the time of flowering (LW).

8. Plant diameter $(\mathrm{cm})$ across the pair of leaves involving the largest leaf (LS).

9. Final height $(\mathrm{cm})$ at the end of the season $(\mathrm{FH})$.

TABLE 5

Minimum experimental sizes for detecting complementary or duplicate epistasis from an experiment using $L_{1 i}, L_{2 i}$ and inbred scores

\begin{tabular}{|c|c|c|c|c|c|c|c|}
\hline \multirow[b]{2}{*}{$h_{n}^{2}$} & \multirow{2}{*}{$\begin{array}{l}\text { Dominance } \\
\text { ratio }\end{array}$} & \multicolumn{6}{|c|}{ Degree of gene association in the tester parents } \\
\hline & & $0 \cdot 00$ & $0 \cdot 20$ & $0 \cdot 40$ & $0 \cdot 60$ & $0 \cdot 80$ & $1 \cdot 00$ \\
\hline \multirow{4}{*}{$0 \cdot 25$} & $0 \cdot 25$ & 1615 & 1680 & 1907 & 2464 & 4165 & 37111 \\
\hline & $0 \cdot 50$ & 1326 & 1380 & 1573 & 2052 & 3578 & 80862 \\
\hline & $0 \cdot 75$ & 1001 & 1043 & 1191 & 1562 & 2766 & * \\
\hline & $1 \cdot 00$ & 719 & 749 & 856 & 1124 & 1998 & * \\
\hline \multirow{4}{*}{$0 \cdot 50$} & $0 \cdot 25$ & 527 & 548 & 622 & 804 & 1359 & 12110 \\
\hline & $0 \cdot 50$ & 403 & 420 & 479 & 625 & 1089 & 24610 \\
\hline & 0.75 & 265 & 276 & 315 & 413 & 731 & 80862 \\
\hline & $1 \cdot 00$ & - & - & - & 225 & 400 & $*$ \\
\hline \multirow{2}{*}{0.75} & $0 \cdot 25$ & - & - & - & 251 & 424 & 3776 \\
\hline & $0 \cdot 50$ & - & - & - & - & 259 & 5860 \\
\hline
\end{tabular}

- As for Table 3.

* Situations for which the experimental sizes cannot be estimated because, theoretically, the epistatic component of variation will be 0.0 with $h_{j} \bumpeq d_{j}$ at each locus.

The data were processed through the university's 1906A Computer to test for the presence of epistasis using Test $1 \mathrm{~b}$ and Test 2. The results are tabulated in table 6 .

We noted earlier from table 2 that Test $1 \mathrm{~b}$ and Test 2 demand $n$ to be 12 and 15 respectively to give the smallest possible experiment for detecting the presence of epistasis. In practice, however, the total experimental sizes may not vary much even if $n$ varies between 9 and 16 for the first case and between 13 and 18 for the second. But an experiment which involves raising $L_{1 i}$, $L_{2 i}$ and $L_{3 i}$ or $P_{i}$ families from 80 inbreds is expected to require a much larger experimental size to detect epistasis with the same precision as an experiment based on 16 inbreds.

The inbreds involved in this experiment, as explained previously, are a random sample of $F_{11}$ inbred lines which could be produced from an $F_{2}$ cross $1 \times 5$ (Perkins and Jinks, 1973). These 80 families are numbered in the order of the random field positions occupied by the $\mathrm{F}_{2}$ plants from which they were derived. Their numbering is, therefore, at random with respect to their origin and performance. Successive sets of 16 inbreds can, therefore, be regarded as independent random samples of pure breeding lines drawn from 
all possible inbreds extractable from the $1 \times 5$ cross. In this way, the experiment can be split into five small experiments of equal size each with $n=16$ and $m=10$. Similarly two successive replicates can be allocated from each of the families raised from all 80 inbreds to give five independent experiments with $n=80$ and $m=2$. This random sub-division of the total

\section{TABLE 6}

Tests of significance for the presence of epistatic variation

\begin{tabular}{|c|c|c|c|c|c|c|c|}
\hline \multirow[b]{2}{*}{ Character } & \multirow[b]{2}{*}{ Item } & \multicolumn{3}{|c|}{ Test Ib } & \multicolumn{3}{|c|}{ Test 2} \\
\hline & & d.f. & M.S. & $\chi^{2}(80)$ & d.f. & M.S. & $\chi^{2}(79)$ \\
\hline \multirow[t]{2}{*}{$\mathrm{H}_{1}$} & Epistasis & 80 & 0.71 & $150 \cdot 0 * * *$ & 79 & 0.97 & $201 \cdot 7 * * *$ \\
\hline & Error & 2155 & $0 \cdot 36$ & & 2155 & $0 \cdot 38$ & \\
\hline \multirow[t]{2}{*}{$\mathrm{H}_{2}$} & Epistasis & 80 & $5 \cdot 35$ & $147 \cdot 2 * * *$ & 79 & 7.97 & $225 \cdot 1 * * *$ \\
\hline & Error & 2155 & $2 \cdot 91$ & & 2155 & $2 \cdot 80$ & \\
\hline \multirow[t]{2}{*}{$\mathrm{H}_{3}$} & Epistasis & 80 & $32 \cdot 35$ & $141 \cdot 0 * * *$ & 79 & $47 \cdot 04$ & $221 \cdot 5 * * *$ \\
\hline & Error & 2155 & $18 \cdot 36$ & & 2155 & $16 \cdot 78$ & \\
\hline \multirow[t]{2}{*}{$\mathrm{F}^{\prime} \mathrm{T}$} & Epistasis & 80 & $4 \cdot 35$ & $119 \cdot 2^{* *}$ & 79 & $7 \cdot 08$ & $194 \cdot 2 * * *$ \\
\hline & Error & 2155 & $2 \cdot 92$ & & 2155 & $2 \cdot 88$ & \\
\hline \multirow[t]{2}{*}{ HFT } & Epistasis & 80 & $22 \cdot 18$ & 91.7 N.S. & 79 & $30 \cdot 10$ & $137 \cdot 1 * *$ \\
\hline & Error & 2155 & $19 \cdot 34$ & & 2155 & $17 \cdot 32$ & \\
\hline \multirow[t]{2}{*}{ CL } & Epistasis & 80 & $0 \cdot 0013$ & $117 \cdot 6 * *$ & 79 & $0 \cdot 0017$ & $193 \cdot 4 * * *$ \\
\hline & Error & 2155 & 0.0009 & & 2155 & 0.0007 & \\
\hline \multirow[t]{2}{*}{ SSP } & Epistasis & 80 & $0 \cdot 0412$ & $76 \cdot 6$ N.S. & 79 & 0.0474 & $103 \cdot 3 *$ \\
\hline & Error & 2155 & 0.0430 & & 2155 & 0.0363 & \\
\hline \multirow[t]{2}{*}{ LL } & Epistasis & 80 & 0.73 & $81 \cdot 1$ N.S. & 79 & $1 \cdot 24$ & $155 \cdot 7 * * *$ \\
\hline & Error & 2155 & 0.94 & & 2155 & 0.63 & \\
\hline \multirow[t]{2}{*}{ LW } & Epistasis & 80 & 0.97 & 82.4 N.S. & 79 & 1.52 & $151.9 * * *$ \\
\hline & Error & 2155 & 0.94 & & 2155 & 0.79 & \\
\hline \multirow[t]{2}{*}{ LS } & Epistasis & 80 & $4 \cdot 66$ & 81.4 N.S. & 79 & $7 \cdot 73$ & $153 \cdot 8 * * *$ \\
\hline & Error & 2155 & 4.58 & & 2155 & 3.97 & \\
\hline \multirow[t]{2}{*}{$\mathrm{FH}$} & Epistasis & 80 & 27.72 & 91.0 N.S. & 79 & $43 \cdot 70$ & $174 \cdot 5 * * *$ \\
\hline & Error & 2155 & $24 \cdot 38$ & & 2155 & $19 \cdot 78$ & \\
\hline
\end{tabular}

data allows us to compare the results obtained from an experiment with $n=16$ with those from the one with $n=80$ within a constant total experimental size.

The analyses were carried out for all the characters but the full details will only be reported for characters $\mathrm{H}_{2}$ (table $7 \mathrm{a}$ ) and FT (table $7 \mathrm{~b}$ ) as these characters are known to take higher (nearer to $0 \cdot 75$ ) $h_{n}^{2}$ values (Eaves and Brumpton, 1972) and show a highly significant epistatic component (table 6) of variation on both tests.

The results for the remaining characters are summarised in table 8. The three probability classes represent significant $(P \leqq 0.05)$, near significant $(0.09 \geqq \mathrm{P} \geqq 0 \cdot 06)$ and non-significant $(1 \cdot 0 \geqq \mathrm{P} \geqq 0 \cdot 1)$ contribution of epistasis to the genetical variation (based on the calculated $\chi^{2}$ value for a test) and the figures given against each of these classes describe the number of experiments (out of a total of five) falling within that probability class for that particular character. 


\section{Discussion}

Experimental sizes given in tables 3,4 and 5 are generally large and they are not only linked to the changing magnitude of epistasis but also to its (classical) type and the degree of gene association in the tester parents. So closely is the detection of epistasis (by Test la and Test $1 \mathrm{~b}$ ) tied to gene association that most of the experiments are impractically large except when ' $r$ ' is greater than 0.6 or unless the heritability is exceptionally high.

TABle 7

Results from tests for epistasis after splitting the data into 5 experiments

(a) Developmental Height $\mathrm{H}_{2}$

\begin{tabular}{|c|c|c|c|c|}
\hline \multirow[b]{2}{*}{$\begin{array}{c}\text { Expt. } \\
\text { no. }\end{array}$} & \multicolumn{2}{|c|}{ Set 1} & \multicolumn{2}{|c|}{ Set 2} \\
\hline & $\begin{array}{c}\text { Test } 1 \mathrm{~b} \\
\chi^{2}(80)\end{array}$ & $\begin{array}{l}\text { Test } 2 \\
\chi^{2}{ }_{(79)}\end{array}$ & $\begin{array}{c}\text { Test 1b } \\
\chi^{2}(16)\end{array}$ & $\begin{array}{c}\text { Test } 2 \\
\chi^{2}(15)\end{array}$ \\
\hline I & $102 \cdot 45^{*}$ & $135 \cdot 45 * * *$ & $19 \cdot 30$ N.S. & $28.44 *$ \\
\hline II & 76.03 N.S. & 98.23 N.S. & $48 \cdot 35 * * *$ & $59 \cdot 33 * * *$ \\
\hline III & $138 \cdot 25 * * *$ & $108 \cdot 15^{*}$ & $17 \cdot 94$ N.S. & $31 \cdot 56 * *$ \\
\hline IV & 100.56 N.S. & $124 \cdot 32 * * *$ & 21.04 N.S. & $49 \cdot 97 * * *$ \\
\hline V & $101.40 *$ & $137 \cdot 06 * * *$ & $30 \cdot 65 *$ & $43 \cdot 16 * * *$ \\
\hline
\end{tabular}

(b) Flowering time FT

\begin{tabular}{|c|c|c|c|c|}
\hline \multirow[b]{2}{*}{$\begin{array}{c}\text { Expt. } \\
\text { no. }\end{array}$} & \multicolumn{2}{|c|}{ Set 1} & \multicolumn{2}{|c|}{ Set 2} \\
\hline & $\begin{array}{c}\text { Test } 1 \mathrm{~b} \\
\chi^{2}{ }_{(80)}\end{array}$ & $\begin{array}{c}\text { Test } 2 \\
\chi^{2}(79)\end{array}$ & $\begin{array}{c}\text { Test 1b } \\
\chi^{2}(16)\end{array}$ & $\begin{array}{c}\text { Test } 2 \\
\chi^{2}(15)\end{array}$ \\
\hline I & $90 \cdot 87$ N.S. & $118 \cdot 31 * *$ & 20.95 N.S. & $26 \cdot 47 *$ \\
\hline II & 92.89 N.S. & $117 \cdot 60 * *$ & $39.97 * * *$ & $49.71 * * *$ \\
\hline III & $118 \cdot 56 * *$ & $101 \cdot 11^{*}$ & 23.87 N.S. & $32 \cdot 36 * *$ \\
\hline IV & 86.63 N.S. & $114 \cdot 81 * *$ & 11.02 N.S. & $39 \cdot 38 * * *$ \\
\hline $\mathrm{V}$ & $105 \cdot 76^{*}$ & $111 \cdot 25 *$ & 18.39 N.S. & $34.91 * *$ \\
\hline
\end{tabular}

The abrupt change in the efficiency of these tests even when heritability is low can be attributed largely to the change in the magnitude of $\sigma_{2}^{2}$ component which includes $\frac{1}{4}[i]^{2}$ as a part of its theoretical expectation. With ' $r$ ' less than $0.5, \frac{1}{4}[i]^{2}\left(\right.$ which when expanded is $\left.\frac{1}{4}\left[\frac{K r^{2}-1}{K-1} \Sigma i_{j k}\right]^{2}\right)$ theoretically takes a value nearer to zero. With increasing values of ' $r$ ' above 0.5 any increase in the linear value of [i] increases the $\sigma_{2}^{2}$ value quadratically. On the other hand, no corresponding changes in the magnitudes of $\Sigma l_{j k}^{2}$ and $\Sigma j_{j k}^{2}$ occur because they are not influenced in the same way by alteration in the ' $r$ ' value. It is therefore quite evident that larger experiments would be required to pick up these effects particularly when Test la or Test $1 \mathrm{~b}$ is applied. Furthermore $\Sigma l_{j k}^{2}$ has little chance of influencing the outcome of the results from Test la because of its relatively small coefficient until and unless a disproportionately large portion of the epistatic variation is of this 
kind. But this is not so for Test $1 \mathrm{~b}$ where its coefficient takes the same value as those of the other components.

The experimental sizes required for Test $1 \mathrm{a}$ and Test $1 \mathrm{~b}$ to detect duplicate epistasis are much smaller than those needed to detect complementary interactions even though the magnitude of the epistasis was kept theoretically

TABLE 8

Summary of the results from the tests of epistasis for the remaining characters in a five-experiment situation

Number of experiments

\begin{tabular}{|c|c|c|c|c|c|}
\hline \multirow{2}{*}{ Character } & \multirow{2}{*}{$\begin{array}{l}\text { Probability of } \\
\chi^{2}(n) \text { value }\end{array}$} & \multicolumn{2}{|c|}{ Set I } & \multicolumn{2}{|c|}{ Set 2} \\
\hline & & Test Ib & Test 2 & Test $1 \mathrm{~b}$ & Test 2 \\
\hline $\mathrm{H}_{1}$ & $\begin{array}{r}1 \cdot 00-0 \cdot 10 \\
0 \cdot 09-0 \cdot 06 \\
\leqq 0 \cdot 05\end{array}$ & $\begin{array}{l}2 \\
0 \\
3\end{array}$ & $\begin{array}{l}1 \\
1 \\
3\end{array}$ & $\begin{array}{l}2 \\
1 \\
2\end{array}$ & $\begin{array}{l}0 \\
0 \\
5\end{array}$ \\
\hline $\mathrm{H}_{3}$ & $\begin{array}{r}1 \cdot 00-0 \cdot 10 \\
0.09-0.06 \\
\leqq 0.05\end{array}$ & $\begin{array}{l}3 \\
0 \\
2\end{array}$ & $\begin{array}{l}0 \\
1 \\
4\end{array}$ & $\begin{array}{l}2 \\
2 \\
1\end{array}$ & $\begin{array}{l}1 \\
0 \\
4\end{array}$ \\
\hline HFT & $\begin{array}{r}1 \cdot 00-0 \cdot 10 \\
0 \cdot 09-0 \cdot 06 \\
\leqq 0 \cdot 05\end{array}$ & $\begin{array}{l}4 \\
0 \\
1\end{array}$ & $\begin{array}{l}3 \\
0 \\
2\end{array}$ & $\begin{array}{l}4 \\
1 \\
0\end{array}$ & $\begin{array}{l}2 \\
1 \\
2\end{array}$ \\
\hline CL & $\begin{array}{r}1 \cdot 00-0 \cdot 10 \\
0 \cdot 09-0.06 \\
\leqq 0.05\end{array}$ & $\begin{array}{l}4 \\
1 \\
0\end{array}$ & $\begin{array}{l}3 \\
0 \\
2\end{array}$ & $\begin{array}{l}3 \\
0 \\
2\end{array}$ & $\begin{array}{l}1 \\
0 \\
4\end{array}$ \\
\hline SSP & $\begin{array}{r}1 \cdot 00-0 \cdot 10 \\
0 \cdot 09-0.06 \\
\leqq 0.05\end{array}$ & $\begin{array}{l}4 \\
1 \\
0\end{array}$ & $\begin{array}{l}4 \\
0 \\
1\end{array}$ & $\begin{array}{l}4 \\
1 \\
0\end{array}$ & $\begin{array}{l}2 \\
1 \\
2\end{array}$ \\
\hline $\mathrm{LL}$ & $\begin{array}{r}1 \cdot 00-0 \cdot 10 \\
0 \cdot 09-0 \cdot 06 \\
\leqq 0 \cdot 05\end{array}$ & $\begin{array}{l}4 \\
0 \\
1\end{array}$ & $\begin{array}{l}4 \\
0 \\
1\end{array}$ & $\begin{array}{l}4 \\
1 \\
0\end{array}$ & $\begin{array}{l}2 \\
0 \\
3\end{array}$ \\
\hline LW & $\begin{array}{r}1 \cdot 00-0 \cdot 10 \\
0 \cdot 09-0.06 \\
\leqq 0 \cdot 05\end{array}$ & $\begin{array}{l}4 \\
0 \\
1\end{array}$ & $\begin{array}{l}3 \\
0 \\
2\end{array}$ & $\begin{array}{l}4 \\
0 \\
1\end{array}$ & $\begin{array}{l}1 \\
1 \\
3\end{array}$ \\
\hline LS & $\begin{array}{r}1 \cdot 00-0 \cdot 10 \\
0.09-0.06 \\
\leqq 0.05\end{array}$ & $\begin{array}{l}3 \\
0 \\
2\end{array}$ & $\begin{array}{l}1 \\
2 \\
2\end{array}$ & $\begin{array}{l}4 \\
1 \\
0\end{array}$ & $\begin{array}{l}2 \\
0 \\
3\end{array}$ \\
\hline FH & $\begin{array}{r}1 \cdot 00-0 \cdot 10 \\
0 \cdot 09-0 \cdot 06 \\
\leqq 0 \cdot 05\end{array}$ & $\begin{array}{l}3 \\
1 \\
1\end{array}$ & $\begin{array}{l}2 \\
0 \\
3\end{array}$ & $\begin{array}{l}4 \\
1 \\
0\end{array}$ & $\begin{array}{l}0 \\
1 \\
4\end{array}$ \\
\hline
\end{tabular}

the same. This is as expected since complementation is expected to increase the variance of the population in such a way that the $\sigma_{1}^{2} / \sigma_{2}^{2}$ ratio is increased and hence the total experimental size required to detect epistasis is also increased. Duplicate genes, on the contrary, reduce the differences between genotypes making the population curve kurtotic and therefore $\sigma_{1}^{2} / \sigma_{2}^{2}$ takes a smaller value leading to a smaller experimental size.

Experiments required to achieve the same level of precision by Test 2 are not so large and are practicable except for low heritabilities and very high ' $r$ ' values. The decrease in the sensitivity of this test for ' $r$ ' $=1.0$ can be 
attributed to the coefficient $\left(-\frac{K r^{2}-1}{K-1}\right)$ of the cross products

$$
\left[\frac{1}{2} \Sigma i_{j k} l_{j k}+\Sigma j_{j k} j_{j k}\right]
$$

which will take a value nearer to -1 and hence effectively neutralise the contributions of the main epistatic effects to $\sigma_{2}^{2}$. This test however does not require different experimental sizes to detect complementary and duplicate types of epistasis.

Both tests (Test $1 \mathrm{~b}$ and Test 2) consistently detect the presence of epistasis for only five of the eleven characters studied. These characters include flowering time and various height measurements which have already been comfirmed as having epistasis as a minor component of their genetic variation (Jinks and Perkins, 1969; Jinks and Perkins, 1970). There is, therefore, little doubt that epistasis is a part of the genetical architecture of these characters and that in this experiment it has been correctly detected by both the tests. The situation is however complicated for the remaining characters for which Test 2 detects significant epistasis but Test $1 \mathrm{~b}$ is not sensitive enough to detect them. For most of these characters, however, there is no independent evidence which can be used to either support or reject the above conclusion. But for Final Height, which has been extensively studied in the $1 \times 5$ cross, there is previous evidence of a low level of predominantly duplicate epistasis (Jinks and Perkins, 1969). The failure of Test $1 \mathrm{~b}$ to detect non-allelic interactions for these characters is, therefore, probably due to the experimental size being too small. The size of experiment required to pick up epistasis for final height when Test $\mathrm{lb}$ is applied can be estimated from its heritability, dominance ratio and ' $r$ ' value.

Final height, together with other height measurements and flowering time, is a highly heritable character (Eaves and Brumpton, 1972). Most of the genes controlling this character $(K \bumpeq 9)$ are dispersed between $P_{1}$ and $P_{5}$ ( $r$ ' $\bumpeq 0.2$; Jinks and Perkins, 1972; Eaves and Brumpton, 1972) and the increasing alleles at most of the loci are partially dominant $(\sqrt{H / D} \bumpeq 0 \cdot 25)$ to the corresponding decreasing alleles. On the basis of this information, it can be readily seen from table 4 that an experiment with 5774 individuals would be required for Test $1 \mathrm{~b}$ to detect epistasis of the level specified in Section 3. Test 2 however would require less than 200 individuals to detect epistasis of similar magnitude under these conditions. The present experiment incorporates 2400 individuals, a number considerably smaller than 5774 and this is most probably the main reason for the failure of Test $1 \mathrm{~b}$ to detect significant epistasis for some of the characters. On the other hand, the present experiment is at least twelve times larger than the one required by Test 2 and that is presumably why it has detected highly significant epistasis for all except one of the characters studied.

An important theoretical prediction which it would be useful to verify in practice is whether we require smaller experiments to detect epistasis when $n$ is kept between say 10 and 18. It looks as though it is true for Test 2 which detects significant epistasis for $\mathrm{H}_{2}$ and FT although the experimental size is down to 480 individuals only. It also detects significant or nearly significant epistasis for 34 out of a total of 45 tests carried out on the rest of the characters. The only cases where it fails to detect non-allelic interactions is where the experiment is smaller than is required theoretically.

Equally, the sensitivity of the test for detecting epistasis should decrease 
with the increase in $n$ value within a fixed experimental size. And this is shown when we compare the results described previously with those obtained by applying Test 2 (table 7, Set 1 ) for $n=80$. Here, it is quite apparent that the average probability of $\chi_{(79)}^{2}$ has increased and hence the significance of epistasis has decreased as compared to the average probability of $\chi_{(15)}^{2}$ and for one experiment the $\chi_{(79)}^{2}$ is not significant. Overall, the $\chi_{(79)}^{2}$ test is able to pick up significant or near significant epistasis on only 24 out of 45 occasions for the remaining characters.

The results obtained from Test $1 \mathrm{~b}$ show epistasis to be relatively unimportant for all the characters. This is expected because 480 is a much smaller experimental size than the one theoretically required for this test to detect non-allelic interactions at the level specified (Section 3). Hence the expected decrease in the sensitivity of the test is observed. Furthermore, there is not much difference between the results obtained from the $n=16$ and $n=80$ samples and it looks, therefore, as though the $n=16$ sample is not appreciably more sensitive when experimental size is too small. In general, however, it can be concluded that Test 2 is more efficient than Test $1 \mathrm{~b}$ under the present circumstances.

\section{Practical implications}

It is indeed significant that the optimal experimental sizes required to detect epistasis depend largely on the gene dispersion in the tester parents. This makes the sensitivity of a test conditional on the ' $r$ ' value and therefore it is possible to lower the minimum limit of the total experimental size by deliberately selecting the tester genotypes. In this way the presence of epistasis can possibly be tested with some certainty, even for the least heritable characters, without conducting particularly large experiments. However, the reduction in experimental sizes for Test la and Test $1 \mathrm{~b}$ can only be achieved if $\Sigma i_{j k}$ is neither absent nor completely ambidirectional. For Test 2, the absence or complete ambidirectional nature of any but not all of the four epistatic components is expected to reduce the experimental size required because, as a consequence, the total effects of the cross-product terms will be considerably reduced (see table 1).

Another major factor which influences the optimal size of the experiment is heritability. The lower the heritability of a character the larger is the size of the experiment required to detect epistasis for that trait. This is because the statistical reliability of the estimates of various genetic parameters is reduced as a result of the masking effects of environmental variation. Therefore, more individuals will be required to restore the accuracy of these estimates. The opposite is of course true for highly heritable traits because the information required to detect epistasis can be easily obtained from relatively few individuals. It will, therefore, be of some help to know the heritability of a character for which the test of epistasis is being planned and such information is sometimes readily available if the material under investigation was extensively studied previously. If, however, a direct estimate of heritability is unavailable, a conservative test of epistasis can be planned and the required experimental size can be obtained by assigning values at the lower end of the range of heritability, dominance ratio and epistasis.

The size of experiment required ultimately depends on the magnitude 
and the type of epistasis prevailing in the material. Most of the experimental sizes given in tables 3,4 and 5 are impracticable and would be unjustified by the level of epistasis present and its importance as a source of variation. However, it is known that relatively smaller experiments would be required to detect epistasis of larger magnitude and if dominance and epistasis are equally important, the experimental sizes required to detect dominance are adequate to detect epistasis as well (see Kearsey, 1970).

Complementary epistasis generally requires larger experiments for its significant detection than duplicate epistasis and the differences are more prominent in low than in medium or high heritability situations. It would be better, therefore, to plan an experiment for the detection of complementary epistasis as this will also be adequate to detect duplicate epistasis, if present.

None of the tests for epistasis is preferable to all others in all circumstances. Test $\mathrm{lb}$ and Test 2 cannot be applied to an $\mathrm{F}_{2}$ population while biometrical geneticists and practical breeders working with diallel populations will be tempted to use Test 2 rather than Text $1 \mathrm{~b}$ because of the extra work involved with the latter. However, Test $1 \mathrm{~b}$ always requires smaller optimal experiments as compared to Test la and therefore should be preferred over the latter wherever possible. If ' $r$ ' $<0.8$, it will always be advantageous to use Test 2 whereas with extreme genotypes as tester parents, maximum information about the epistasis can be extracted by using either Test la or Test $1 \mathrm{~b}$.

Acknowledgments. - These are due to Dr M. J. Kearsey for his useful advice on the preparation of this paper. The investigation was supported by an SRG studentship.

\section{REFERENCES}

EAVEs, L. J., AND BRUmpton, R. J. 1972. Factors of covariation in Nicotiana rustica. Heredity, 29, $15 \mathrm{I}-175$.

JINKs, J. L., AND JONEs, R. M. 1958. Estimation of the components of heterosis. Genetics, $43,63-85$.

JiNKs, J. L., AND PERKins, J. M. I969. The detection of linked epistatic genes for a metrical trait. Heredity, 24, 465-475.

JINKs, J. L., AND PERKINs, J. M. 1970. A general method of detecting additive, dominance and epistatic components of variation: III. $\mathbf{F}_{\mathbf{2}}$ and backcross populations. Heredity, 25, 419-429.

Jinks, J. L., AND PERKins, J. M. I972. Predicting the range of inbred lines. Heredity, 28, 399-403.

JINKS, J. L., PERKINS, J. M., AND BREESE, E. L. 1969. A general method of detecting additive, dominance and epistatic variation for metrical traits: II. Application to inbred lines. Heredity, 24, 45-57.

KEARSEY, M. J. 1970. Experimental sizes for detecting dominance variation. Heredity, 25, 529-542.

KEARSEY, M. J., AND JINKS, J. L. 1968. A general method of detecting additive dominance and epistatic variation for metrical traits: I. Theory. Heredity, 23, 403-409.

MAther, K., AND Jinks, J. L. 1971. Biometrical Genetics, 2nd edition. Chapman and Hall, London.

MATHER, K., AND vines, A. 1952. The inheritance of height and flowering time in a cross of Nicotiana rustica. Quantitative Inheritance, ed. E. C. Reeve, pp. 49-80. C. H. Waddington, London.

PEDERSON, D. G. 197I. The estimation of heritability and degree of dominance from a diallel cross. Heredity, 27, 247-264.

PERKINS, J. M., AND JINKs, J. L. 1970. Detection and estimation of genotype-environmental, linkage and epistatic components of variation for a metrical trait. Heredity, 25, 157-177.

PERKINS, J. M., AND JINKs, J. L. 1973. The assessment and specificity of environmental and genotype-environmental components of variability. Heredity, 30, 111-126.

VAN DER VEEN, J. H. I959. Tests of non-allelic interaction and linkage for quantitative characters in generations derived from two diploid pure lines. Genetica, 30, 201-232. 